\title{
De volatiliteit van de middengroepen
}

\author{
Wouter van der Brug \& Tom van der Meer
}

\section{Introductie}

In politicologisch onderzoek naar democratische stabiliteit wordt vanouds een belangrijke rol toegekend aan de middenklasse. Landen met een hoog welvaartsniveau, een hoog gemiddeld opleidingsniveau, een niet al te scheve inkomensverdeling en een grote middenklasse hebben meer kans om democratisch te zijn en te blijven dan landen waarin minder aan deze voorwaarden wordt voldaan. De middenklasse speelt daarnaast een belangrijke rol in democratiseringsbewegingen in autoritaire staten (zie bijvoorbeeld Lipset, 1959; Burkhart \& Lewis- Beck, 1994; Przeworski e.a., 2000). Als de middenklasse krimpt en de inkomensongelijkheid toeneemt, zou dit dus slecht nieuws zijn voor de stabiliteit van de democratie.

$\mathrm{Nu}$ zal de soep in Nederland niet meteen zo heet worden gegeten als deze hierboven wordt opgediend. Nederland behoort in internationaal vergelijkend perspectief nog steeds tot de groep landen met relatief kleine inkomensverschillen en een grote middenklasse. Daarnaast bestaat er zeer brede steun voor de idealen en principes van democratisch bestuur en er zijn geen redenen te verwachten dat deze steun afneemt. Als de middenklasse onder druk staat, zou dit echter wel gevolgen kunnen hebben voor een andere vorm van stabiliteit, namelijk de stabiliteit van verkiezingsuitslagen. Daarover gaat dit artikel. In hoeverre is er sprake van volatiliteit van kiezers in het midden?

Die stabiliteit van verkiezingsuitslagen is in Nederland fors afgenomen. Bij opeenvolgende verkiezingen veranderen aanzienlijk meer kiezers van partij dan voorheen. Vooralsnog vormde 2002, met de opkomst van Fortuyn en de forse groei van het CDA van Balkenende, een hoogtepunt. Maar liefst 31 procent van de Tweede Kamerzetels wisselde toen van eigenaar. De verkiezingen van 12 september 2012 waren uiteindelijk minder instabiel (15 procent), mede door de forse terugval van de SP in de laatste campagnemaand. Al met al is het heel gebruikelijk dat kiezers tijdens verkiezingen, maar zeker ook tussentijds, van partijvoorkeur veranderen (Van der Meer e.a., 2012). Deze bijdrage richt zich op de vraag welke rol de middenklasse speelt in de instabiliteit in verkiezingsuitslagen die we in Nederland zien.

Empirisch gezien zijn er twee patronen denkbaar. Vanuit de klassieke sociologische literatuur zouden we verwachten dat de middenklasse de meest stabiele factor is in het politieke spectrum. Voor zover dit het geval is, zou een afname van de middenklasse leiden tot minder stabiliteit. Het is echter ook denkbaar dat als de middenklasse onder druk staat, dit juist zou leiden tot minder stabiliteit onder

* Prof. dr. Wouter van der Brug is hoogleraar aan de Universiteit van Amsterdam, afdeling Politicologie. W.vanderBrug@uva.nl Dr. Tom van der Meer is universitair hoofddocent aan de Universiteit van Amsterdam, afdeling Politicologie. t.w.g.vandermeer@uva.nl 
deze groepen. Ook is het denkbaar dat veel partijen zich juist richten op de middengroepen en dat deze kiezers daarom sneller zullen switchen tussen partijen die ideologisch weinig van elkaar verschillen. Dit laatste patroon leidt weliswaar tot meer volatiliteit in verkiezingsuitslagen, maar tot weinig instabiliteit van het politieke stelsel, omdat men switcht tussen gematigde partijen.

Commentatoren op de opiniepagina's van kranten en tijdschriften zijn vaak negatief over de (toegenomen) electorale instabiliteit. Deze wordt veelvuldig toegeschreven aan het feit dat kiezers wispelturig en gebrekkig geïnformeerd zijn. Kees Schuyt sprak over Nederlandse kiezers als 'stuifzand'. Mark Kranenburg sprak over electorale voorkeuren als een 'flipperkast'. Hans van Mierlo in Vrij Nederland: 'De kiezers doen maar wat. Die pakken elke trein die voorbijkomt en er een beetje leuk uitziet.' Wim Deetman duidde Nederlandse kiezers aan als 'emotioneel, irrationeel of intuïtief'.

Wij vinden het van belang te benadrukken dat we dit negatieve beeld niet onderschrijven. Een van de belangrijkste functies van verkiezingen is dat deze met enige regelmaat leiden tot een vreedzame verandering in de samenstelling van de regering. Als een regering nooit wordt weggestemd en men ook geen angst hoeft te hebben weggestemd te worden, dan ontbreekt de prikkel rekening te houden met de wensen van de bevolking. In een democratie zou men normatief gesproken dus ook mogen verwachten dat kiezers machthebbers verantwoordelijk houden voor het gevoerde beleid en dus bereid zijn hen weg te stemmen. Bij een hoge mate van stabiliteit in verkiezingsuitslagen kan men zich juist afvragen of kiezers wel kritisch genoeg zijn. In zekere zin kan dus worden gesteld dat een hoge mate van instabiliteit in verkiezingsuitslagen juist aantoont dat kiezers doen wat zij behoren te doen: hun vertegenwoordigers kritisch en met een zekere argwaan volgen en waar nodig wegstemmen (zie ook Van der Brug \& Van der Eijk, 2003; Andeweg \& Thomassen, 2011; Van der Meer e.a., 2012). Uiteraard is niet alles koek en ei. Voor zover kiezers inderdaad wispelturig zijn en eenvoudig switchen tussen sterk uiteenlopende partijen, en wanneer politieke partijen zich gedwongen voelen daar opportunistisch op te reageren, ondermijnt dat de stabiliteit van beleidsprocessen. Ook maakt dit een carrière in de politiek onaantrekkelijk.

In deze bijdrage zullen we daarom een onderscheid maken tussen de neiging te switchen tussen ideologisch verwante partijen en de neiging te switchen tussen ideologisch (zeer) verschillende partijen. Centraal hierbij staat de vraag: hoe veranderlijk of wispelturig zijn de middengroepen ten opzichte van andere groepen burgers? Deze vraag kan alleen worden beantwoord indien men op individueel niveau beschikt over data over kiezersvoorkeuren van verschillende groepen kiezers op meerdere tijdstippen. In deze bijdrage maken wij hiertoe gebruik van data afkomstig uit het EenVandaag Opiniepanel. ${ }^{1}$

\section{Opzet van de studie}

In deze bijdrage maken we gebruik van de uitgebreide panelgegevens uit het EenVandaag Opiniepanel (1VOP), verzameld door het actualiteitenprogramma EenVandaag. Hoewel het 1VOP een zelfaanmeldingspanel is en deelnemers voor 
elke peiling apart worden verzocht deel te nemen, is het een valide bestand gebleken om verbanden bloot te leggen. Door de grootte en diversiteit van het deelnemersbestand blijkt er bijvoorbeeld een correlatie van 0,998 tussen de verkiezingsuitslag van 2010 in 1VOP en de feitelijke verkiezingsuitslag wanneer we controleren voor stemgedrag tijdens de verkiezingen van 2006.

Het bestand omvat (maximaal) 42 peilingen tussen de Tweede Kamerverkiezingen van 9 juni 2010 en de Tweede Kamerverkiezingen van 12 september 2012. Uit de analyses blijkt dat deze sterk worden beïnvloed door de buitengewoon massale overstap van SP-kiezers naar de PvdA in de laatste weken voor de verkiezingen van 2012. Daarom beperken we onze analyse tot de periode juni 2010augustus 2012, hoewel we ook de bijzondere campagne van 2012 zullen bespreken. In totaal omvat dit bestand 30.769 1VOP-deelnemers die aan minstens twee peilingen hebben deelgenomen. Met deze gegevens kunnen we nauwkeurig nagaan welke kiezers wanneer en op welke wijze van partijvoorkeur veranderen. Op basis van deze gegevens hebben we drie maten geconstrueerd om de afhankelijke variabele 'veranderlijkheid' te meten:

- Of men 'überhaupt' wel eens van partijvoorkeur is veranderd in deze periode.

Diegenen die minimaal twee keer een andere partij aangaven als de partij waarop zij van plan waren te gaan stemmen, krijgen op deze score een 1 . Andere respondenten scoren een 0.

- Hoe vaak men van partij switchte. Elke keer als men bij een interviewronde een andere partij noemt dan in de vorige, komt er een punt bij.

- Of men ooit wisselt tussen twee partijen die ideologisch verschillend zijn. Dit zijn wisselingen tussen een linkse (SP, GroenLinks, PvdA) en een rechtse (CDA, VVD, PVV) partij en wisselingen tussen D66 en de PVV.

We zullen de resultaten tonen van analyses met deze drie afhankelijke variabelen. Er zijn twee manieren om aan te kijken tegen de onafhankelijke variabele in deze studie: 'de middengroepen'. De eerste manier zouden we de 'sociologische' indeling kunnen noemen, die groepen kiezers onderscheidt op basis van maatschappelijke achtergrondkenmerken, zoals opleiding, inkomen en/of de subjectieve inschatting van de sociale klasse waartoe men behoort. Vanwege de beschikbaarheid van data kijken we naar twee soorten achtergrondkenmerken: opleidings- en inkomensniveau.

De tweede manier is de meer 'politicologische' indeling, dus of men politiekideologisch tot het midden behoort. Dit kan worden afgemeten aan de positie die men inneemt op een elfpunts links-rechtsschaal, lopend van 0 ('links') tot 10 ('rechts'). Kiezers die zich ergens rond de 5 positioneren op deze schaal beschouwen zichzelf ideologisch als behorend tot het politieke midden.

In deze studie zullen we op beide manieren het switchgedrag van groepen burgers in kaart brengen. We zullen zowel kijken naar het switchgedrag van groepen burgers die we op basis van hun achtergrondkenmerken als 'middengroepen' kunnen aanduiden, als naar het switchgedrag van de ideologische middengroepen. 


\section{Resultaten}

Bijna 35\% van de deelnemers van het EenVandaag Opiniepanel veranderde tussen de verkiezingen van 2010 en 2012 minstens één keer van partijvoorkeur in de peilingen waaraan zij deelnamen. Een aanzienlijk deel van de veranderingen vond plaats in de allerlaatste weken voor de verkiezingen. Wanneer we de peilingen afkappen tot eind augustus 2012, valt het percentage veranderlijke kiezers terug naar bijna 30 procent (29,8 procent). Gemiddeld genomen verandert iedere respondent in 4 procent van de peilingen waaraan zij deelnemen van partijvoorkeur. Dat is aanzienlijk minder frequent dan in de periode 2006-2010 (Van der Meer e.a., 2012), waarbinnen overigens ook de opkomst en ondergang van Trots op Nederland en de groei van de PVV van 9 naar 24 zetels vielen. Voor een aanzienlijk deel komen de grote veranderingen in de laatste weken op het conto van de overstap van SP'ers naar de PvdA; een kleiner deel valt te herleiden tot de groei van de VVD in de laatste weken. We richten ons daarom op de periode van juni 2010 tot augustus 2012, direct voor de laatste campagneweken.

Alvorens we de mate waarin kiezers veranderen uitsplitsen naar inkomensgroep, opleidingsniveau en ideologische positie willen we kort iets zeggen over de partijvoorkeuren van de middengroepen. Kiezers die zich ideologisch in het midden plaatsen, stemmen relatief vaak op het CDA en D66, en zitten verder netjes op de schaal tussen SP, GroenLinks, PvdA (links) en VVD en PVV (rechts). Inkomensmiddengroepen stemmen vaker op het CDA en de PvdA; inkomen staat nagenoeg los van een stem op de PVV. Middelbaar opgeleiden stemmen minder vaak PvdA. Opleiding staat nagenoeg los van stemmen op het CDA, maar hangt wel sterk samen met een stem voor GroenLinks en D66, die relatief hoogopgeleide kiezers trekken, en de PVV (een partij die relatief weinig hoogopgeleide kiezers trekt). Als algeheel beeld kunnen we zeggen dat het overgrote deel van de middengroepen op relatief gematigde partijen stemt.

De figuren 1-3 laten de verschillen zien tussen de maatschappelijke groepen in de neiging te veranderen. De figuren tonen de percentages respondenten die minstens één keer van partijvoorkeur veranderden; wanneer we deze zouden uitzetten tegenover de frequentie van veranderlijkheid zien we eenzelfde beeld. 


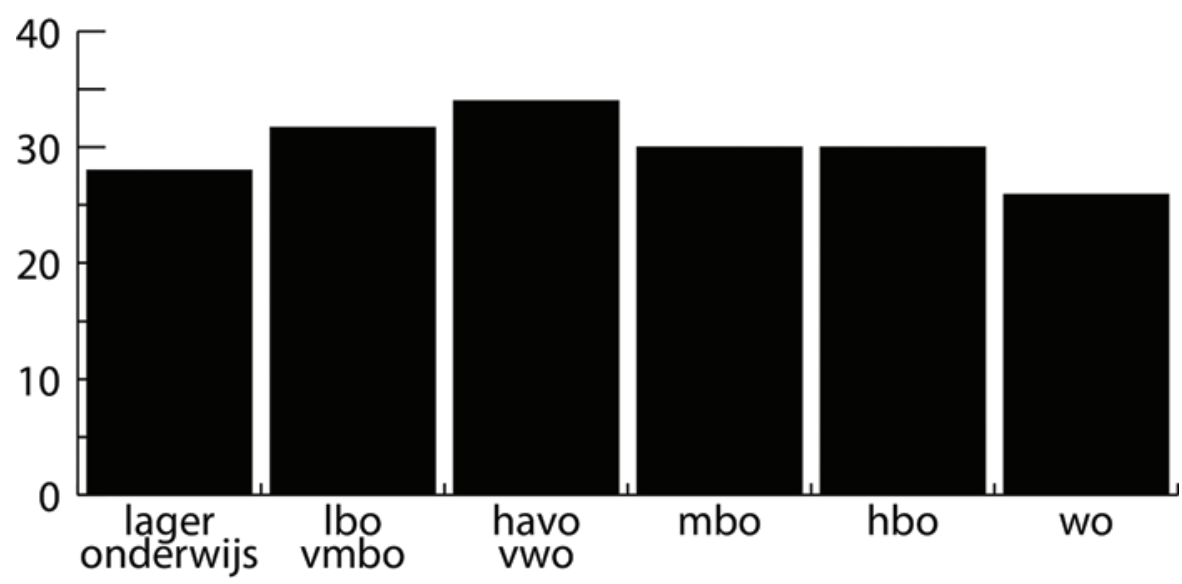

Figuur 1

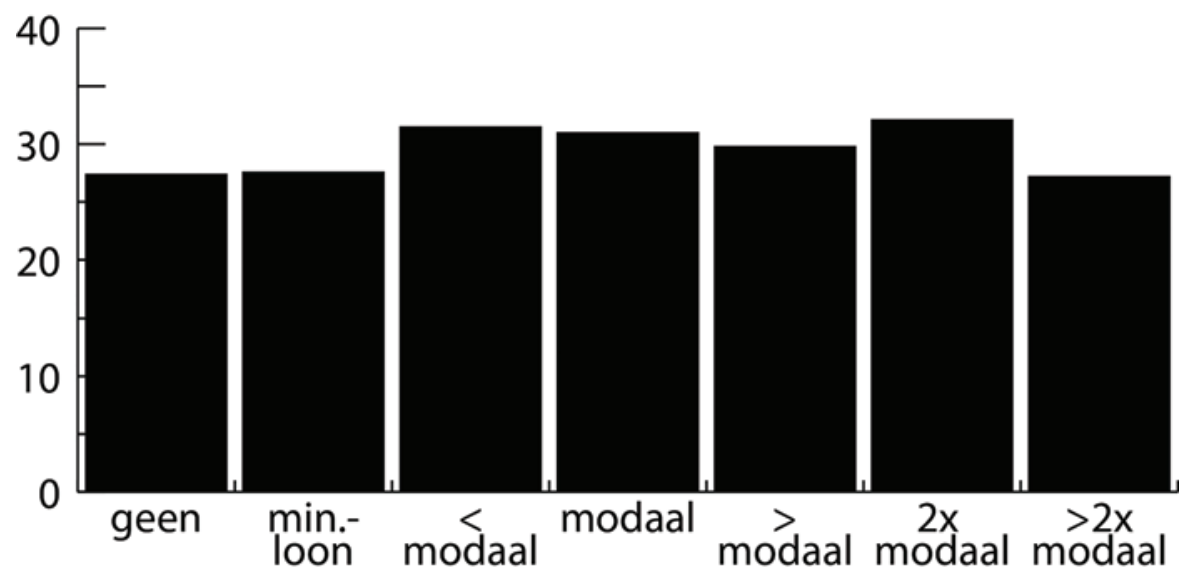

Figuur 2

De figuren 1-3 laten in de eerste plaats zien dat volatiele partijvoorkeuren onder alle groepen voorkomen; de verschillen zijn betrekkelijk klein. Onder alle deelgroepen veranderde minstens 25,9 procent van de respondenten van partijvoorkeur. Onder alle deelgroepen bleef dit percentage onder de 35,2 procent. Ten tweede zien we dat de middengroepen volatieler zijn dan de andere groepen. Van de opleidingsgroepen is de volatiliteit het hoogst onder diegenen met een havo-/ vwo-opleiding (34 procent) en is ze lager naarmate kiezers hoger of juist lager opgeleid zijn. Degenen met alleen lager onderwijs (28 procent) en degenen met een universitaire achtergrond (26 procent) zijn het minst geneigd te veranderen. Bij de inkomenscategorieën zien we eenzelfde onderscheid, zij het minder uitgesproken: degenen met een laag inkomen (geen inkomen of minimumloon) en 


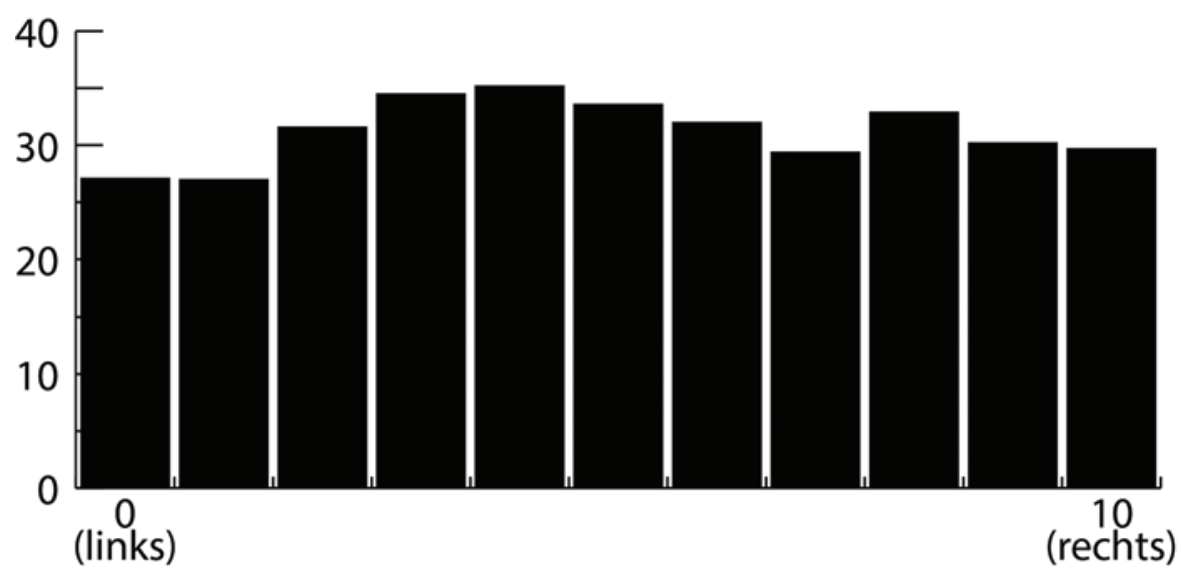

Figuur 3

degenen met een hoog inkomen (meer dan twee keer modaal) veranderen wat minder vaak dan de middengroepen.

Een iets groter verschil zien we weer bij de politiek-inhoudelijke indeling van kiezers in links-rechtstermen. Van de meest linkse kiezers (scores 0 en 1 op de linksrechtsschaal) verandert minstens 27 procent eens van partijvoorkeur, en van de meest rechtse kiezers (score 10) is dat 30 procent, dit in vergelijking met 34 procent van de kiezers die zich in het midden positioneren (op 5) of 35 procent van de kiezers net links daarvan (score 4$){ }^{2}$

Op zichzelf kan de mate van veranderlijkheid van middengroepen wijzen op zelfbewuste, kieskeurige burgers die kiezen tussen ideologisch verwante partijen, maar ook op kiezers aan wie de structuur in het partijsysteem weinig houvast biedt. Daarom maken we nog een verdere uitsplitsing. We kijken nu niet naar veranderlijkheid in het algemeen, maar richten ons op de vraag hoeveel van de 9133 veranderlijke respondenten switchen tussen partijen die in ideologisch opzicht ver van elkaar af staan.

Veruit de meeste kiezers veranderen binnen ideologisch consistente blokken (zie ook Van der Meer e.a., 2012). Toch switcht exact een kwart van de volatiele respondenten (circa 10 procent van alle respondenten) tussen politieke partijen die ideologisch niet verwant zijn, dus tussen een linkse en een rechtse partij. Dit zijn in deze periode, tijdens de gedoogconstructie rond het kabinet-Rutte I, vooral kiezers die van de PVV naar de SP trekken. Mogelijkerwijs zijn dit kiezers die beide partijen aantrekkelijk vinden vanwege het feit dat zij zich richten tegen de gevestigde partijen. Ook kan het dat deze kiezers de SP en de PVV om verschillende redenen aantrekkelijk vinden (de SP vanwege het sociaaleconomisch beleid dat deze partij voorstaat en de PVV vanwege de standpunten op migratie en de Europese Unie, bijvoorbeeld). 


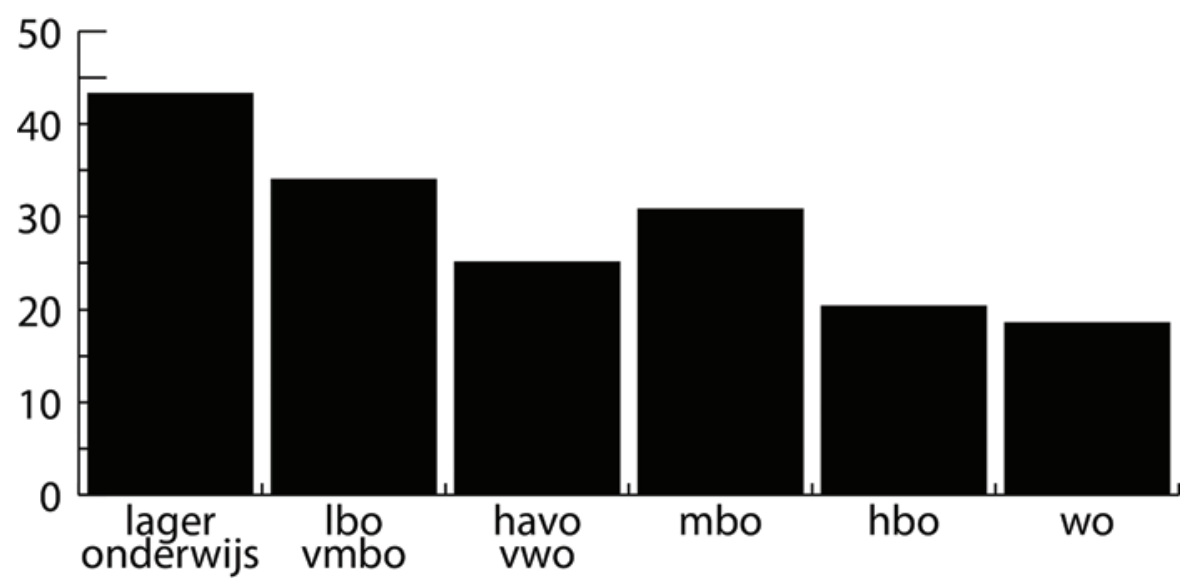

Figuur 4

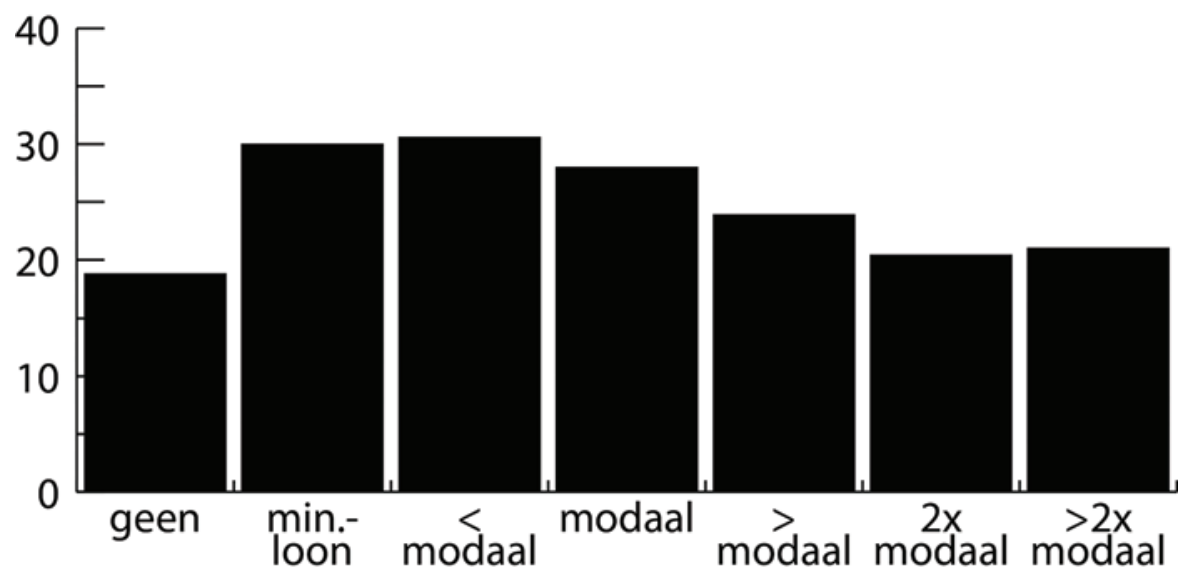

Figuur 5

Figuren 4-6 splitsen de volatiele kiezers verder uit naar degenen die switchen tussen ideologisch niet verwante partijen. Wanneer we kijken naar opleidingsniveau, blijken met name de laagst opgeleide kiezers in groten getale te bewegen tussen partijen die relatief ver van elkaar afstaan. De hoogst opgeleide respondenten die veranderen van partijvoorkeur wisselen het minst tussen niet-verwante partijen (18,6 procent). Ook bij de inkomenscategorieën blijken niet de middeninkomens maar de lage inkomens vaker te switchen tussen partijen die ver van elkaar afstaan. ${ }^{3}$

We zien een ander beeld wanneer we kiezers uitsplitsen naar links-rechtspositie. Het patroon is hier allerminst lineair. De respondenten op de uiterste extremen veranderen vaker dan iets gematigder maar nog altijd uitgesproken respondenten: 23 procent van de switchers onder de meest linkse respondenten (0) en 30 procent van de switchers onder de meest rechtse respondenten (10) wisselden 


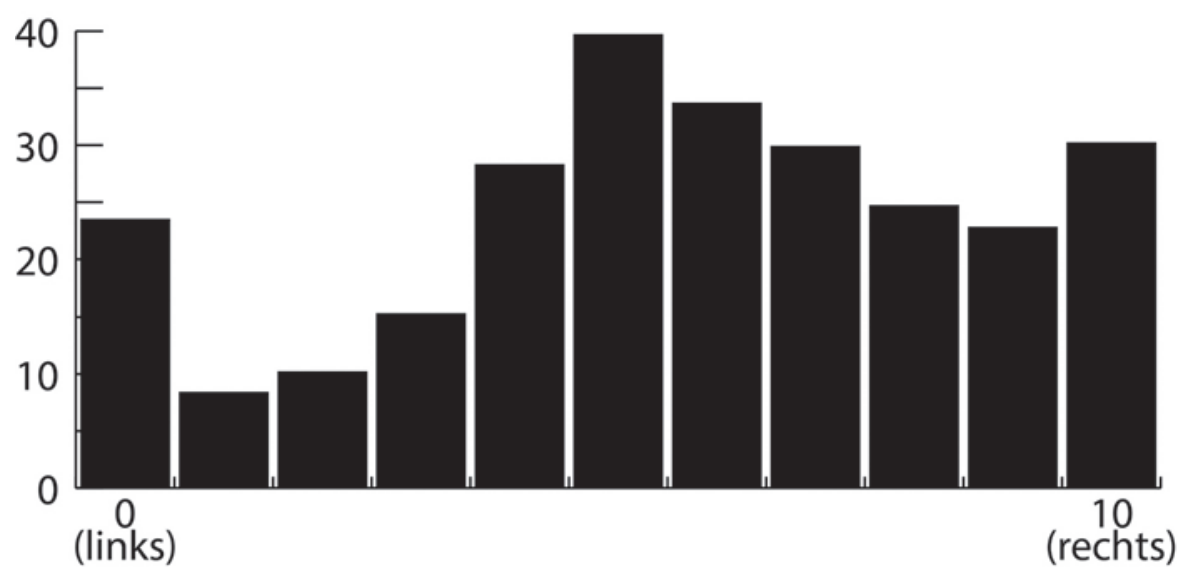

\section{Figuur 6}

wel eens tussen partijen die ver van elkaar afstaan. De grootste groep zien we echter in het politieke midden (40 procent) en direct rechts daarvan (34 procent). De minst veranderlijke kiezers nemen een uitgesproken maar niet extreem linkse positie in (scores 1-3, met respectievelijk 8 procent, 10 procent en 15 procent), of een uitgesproken maar niet extreem rechtse positie (scores 8-9, met respectievelijk 25 procent en 23 procent).

Wat betekent dit? De combinatie van demografische en politiek-ideologische patronen wijst er volgens ons niet op dat de politieke middengroepen vluchtiger stemgedrag zouden vertonen. Eerder wijst het erop dat kiezers die twijfelen tussen partijen die op conventionele politieke scheidslijnen niet op elkaar lijken (als SP en PVV, of PVV en D66), moeite hebben zichzelf te positioneren op de eendimensionale links-rechtsschaal. Daarom vinden we hen terug op de extremen (waar in het hoefijzermodel van de politiek de politieke extremen elkaar vinden in anti-establishment houdingen), maar ook in het politieke midden. Deze kiezers laten zich immers niet eenvoudig vangen in een traditioneel links-rechtsschema.

\section{Conclusie}

Een van de meest opmerkelijke resultaten van deze studie is dat de middengroepen vaker van partijvoorkeuren veranderen dan andere groepen kiezers. Of men kiezers nu onderscheidt op basis van hun opleiding en inkomen of op basis van hun ideologie, het zijn steeds de middengroepen die het meest geneigd zijn van partijvoorkeur te wisselen. Binnen het kader van dit themanummer over de middenklasse die in de knel zit, zou men wellicht geneigd zijn de conclusie te trekken dat de onzekerheid van de middenklasse zich politiek vertaalt in een grotere neiging te wisselen. Wij denken niet dat onze gegevens een dergelijke conclusie rechtvaardigen. Ten eerste zijn de verschillen tussen de groepen betrekkelijk klein. Ten tweede wisselen de middengroepen weliswaar vaker dan andere groepen, maar doen zij dit niet vaker tussen groepen die aan verschillende kanten van 
het ideologisch spectrum staan. Het switchen tussen ideologisch niet-verwante partijen komt vooral vaker voor onder lager opgeleide kiezers en onder kiezers met een laag inkomen.

Dat de middengroepen vaker veranderen, kan dus ook worden verklaard vanuit de aanbodkant. Veel partijen concurreren om de stem van de kiezers in het midden en die partijen verschillen ideologisch niet zoveel van elkaar. De economische en politieke middengroepen hebben ook minder eenduidige belangen en in deze situatie is de overstap van de ene naar de andere verwante en ont-ideologiseerde partij gemakkelijk gemaakt. Het is belangrijk te benadrukken dat juist de minst veranderlijke kiezers te vinden zijn aan de flanken: (radicaal) links zowel als (radicaal) rechts. De sterke veranderlijkheid van de middengroepen kan dus ook worden beschouwd als een bewijs voor een toegenomen emancipatie onder deze kiezers. Zij trekken niet richting radicale partijen, maar switchen wel gemakkelijker tussen de meer gematigde partijen.

\section{Noten}

1 Paneldata waarin dezelfde kiezers over een langere periode worden onderzocht om vast te stellen wie wanneer van vertrouwen of partijvoorkeur verandert, zijn bijzonder schaars (zie bijvoorbeeld Bartolini \& Mair, 1990; Kuhn, 2009). Tot voor kort waren studies naar veranderende voorkeuren van kiezers daarom veelal beperkt tot twee of drie metingen in een campagneperiode (zie onder andere Anker, 1994; Van der Kolk, 2000). Het EenVandaag Opiniepanel biedt de mogelijkheid om over een langere periode en ook buiten campagneperiodes te kijken naar wisselingen in kiezersvoorkeuren.

2 Deze uitkomsten blijven overeind wanneer we ze onderzoeken in een multivariate regressieanalyse, waarbij we controleren voor andere achtergrondkenmerken en voor de frequentie van deelname aan peilingen. Immers, kiezers die vaker deelnemen aan peilingen van het 1 VOP hebben daardoor meer mogelijkheden om minstens eens van mening te veranderen.

3 De lage score van de laagste inkomensgroep kan niet los worden gezien van het kleine aantal respondenten in deze groep.

\section{Literatuur}

Andeweg, R.B., \& Thomassen, J.J.A. (2011). Van afspiegelen naar afrekenen? De toekomst van de Nederlandse democratie. Leiden: Leiden University Press.

Anker, H. (1994). Is de Nederlandse kiezer op drift geraakt?. In: Jaarboek Nederlandse Politieke Partijen 1993. Groningen: Documentatiecentrum Nederlandse Politieke Partijen, 145-164.

Bartolini, S., \& Mair, P. (1990). Identity, competition, and electoral availability: The stabilization of European electorates, 1885-1985. Cambridge: CUP.

Brug, W. van der, \& Eijk, C. van der (2003). Enige nuances: misverstanden over kiezers in het algemeen en de verkiezingen van 2002/2003 in het bijzonder. In: C. Coops, 
C. van der Eijk, P. Kramer \& B. Pauw (red.), Een politieke aardverschuiving. Alphen a/d Rijn: Kluwer.

Burkhart, R.E., \& Lewis-Beck, M.S. (1994). Comparative democracy: The economic developments thesis. American Political Science Review, 88: 903-910.

Kolk, H. van der (2000). Aarzelende, wisselende en zwevende kiezers. In: J.J.A. Thomassen, K. Aarts \& H. van der Kolk (red.), Politieke veranderingen in Nederland, Den Haag: Sdu Uitgevers, 93-106.

Kranenburg, M. (2003, 11 januari). De flipperkast-democratie. NRC Handelsblad.

Kuhn, U. (2009). Stability and change in party preference. Swiss Political Science Review, 15 (3): 463-494.

Lipset, S. (1959). Some social requisites of democracy: Economic development and political legitimacy. American Political Science Review, 53: 69-105.

Meer, T. van der, Elsas, E. van, Lubbe, R., \& Brug, W. van der (2012). Kieskeurige kiezers. Een panelstudie naar de veranderlijkheid van partijvoorkeuren. Beleid en Maatschappij, 39 (2): 153-178.

Przeworski, A., Alvarez, M., Cheibub, J.A., \& Limongi, F. (2000). Democracy and development: Political institutions and well-being in the world, 1950-1990. Cambridge: Cambridge University Press.

Schuyt, K. (2003, 15 januari). Kiezers als stuifzand. De Volkskrant.

Wezel, M. van, \& Broer, Th. (2009, 25 april). 'De kiezers doen maar wat': Dubbelinterview Hans van Mierlo en Alexander Pechtold. Vrij Nederland. 